\title{
REVIEW
}

\section{Complementary and Alternative Therapies for Pregnant Women Suffering from Constipation: A Systematic Review}

\author{
Ayca Solt Kirca $^{1^{*}}$ iD Sena Dilek Aksoy ${ }^{2}$ iD \\ ${ }^{1}$ Kirklareli University School of Health, Midwifery Depertmant Kirklareli, Turkey. \\ ${ }^{2}$ Kocaeli University School of Health, Midwifery Depertmant, Kocaeli \\ * Corresponding Author: Ayca Solt Kirca, e-mail: aycasolt@gmail.com
}

Received: 04.05.2021 Accepted: 04.06.2021

\begin{abstract}
Background: Constipation is one of the most common gastrointestinal symptoms in pregnant women.

Purpose: This study was aimed at determining the effects of complementary and alternative therapy methods on the symptoms of pregnancy-related constipation.

Search strategy: The authors performed a systematic search according to PRISMA guidelines. The database Web of Science, Scopus, EMBASE, CENTRAL, national databases were screened to reach studies published from January 2010 to March 2020 with restriction to human studies in English or Turkish language. The quality of the studies included in the study was assessed with the measurement tool proposed in the JADAD, JBI, and Observational Open-Label Studies scales.

Inclusion criteria: Electronic searches were conducted in PubMed using the keywords constipation "pregnancy" or pregnant woman and "acupuncture" or "acupressure" or "massage" or "herbal medicine" or "aromatherapy" or "music therapy" or "homeopathy" or "hypnosis" or "meditation" or "reflexology" or "moxibustion" or "ayurvedic Medicine" or "ayurveda" or "Traditional Iranian Medicine

Data extraction and analysis: Selection of included articles, data extraction and methodological quality assessments were respectively conducted by two review authors.

Findings: 14536 studies were selected and 706 studies were screened based on their titles and abstracts. Seventy-three studies were analyzed in detail to assess whether they were suitable. In order to find a larger number of original articles, of the studies in the reference lists of these studies, those found in the electronical environment were screened, but no studies were found to meet the inclusion criteria. Finally, 3 studies were included in the study.

Conclusions: The results demonstrated that herbal medicine and foot reflexology reduced constipation complaints during pregnancy without any side effects. Because the number of studies conducted to investigate the efficacy and safety of different types of complementary and alternative medicine methods in pregnant women with constipation is very few, more studies should be carried out on the issue.
\end{abstract}

Key words: Complementary and Alternative Medicine, Pregnancy Care, Constipation

What is already known about the topic: One of the leading complaints during pregnancy is constipation. In recent years, the use of complementary and alternative medicine instead of pharmacological drugs for the alleviation of such complaints has drawn more attention.

What do the results of this study add: Performing a larger number of randomized controlled studies to assess the effects of Complementary and Alternative Therapy methods on pregnancy-related constipation may be effective in reducing the need for pharmacological methods to be used during pregnancy.

What are the implications of these findings for clinical practice and or further research:

Complementary and Alternative Therapies are easy to apply and cost-effective methods and play a significant role in reducing constipation. Performing more studies on the use of CAM methods will provide an alternative option for pregnant women who do not want to resort topharmacological methods.

\section{INTRODUCTION}

Constipation is one of the most common symptoms of gastrointestinal complaints in pregnant women. ${ }^{1,2}$ Pregnancy-related constipation affects the daily life of women negatively. ${ }^{1}$ In Rungsiprakan et al.'s systematic review (2015), the rate of constipation during pregnancy ranges between $11 \%$ and $44 \% .^{3}$ According to the results of studies conducted in Turkey, the rate of constipation in pregnant women varies between $38.8 \%$ and $47 \%$., 4 The etiology of constipation that occurs during pregnancy is 


\section{Volume: 2 Issue: 2 \\ Year: 2021 \\ DOI: $10.53811 /$ ijtcmr.932397

multifactorial. One of these factors is that the pelvic organs and the structures supporting the urethra (levator ani muscle and anal sphincters) that are primarily responsible for the defecation process undergo changes due to the increase in the internal abdominal pressure during pregnancy. ${ }^{2}$ Another factor is the decrease in bowel movements caused by the increase in the hormone progesterone level during pregnancy. In addition, the enlargement of the uterus, a decrease in the activities of daily living of the mother, stress, taking iron and calcium preparations, inadequate fluid consumption and changes in diet cause constipation more frequently during pregnancy. ${ }^{1,6-8}$ The review of the literature demonstrated that pregnancy-related constipation (both difficult defecation and the feeling of not being able to empty fully) is common in every trimester of pregnancy. ${ }^{9-11}$

Among the pharmacological methods used for constipation are the use of stool softeners, prokinetic agents, osmotic agents and stimulant laxatives. ${ }^{1,12}$ These pharmacological methods used during pregnancy can negatively affect the health of both the mother and the fetus. ${ }^{13-15}$ According to clinical guidelines, no clinical recommendations have been made for the treatment of constipation during pregnancy. ${ }^{1,12}$ Today, the choice of treatment for the pregnancy-related constipation remains a challenging clinical problem. The National Center for Complementary and Integrative Health (NCCIH) defines the Complementary and Alternative Medicine (CAM) as a healthcare approach not considered as a part of the general Western or traditional medicine. ${ }^{16}$ While the term 'complementary medicine' refers to treatments used together with conventional medical treatments, the term 'alternative medicine' refers to treatments used instead of conventional medical treatments. ${ }^{16}$ In many parts of the world, the use of CAM to reduce such problems as nausea, vomiting, labor pain, low back pain, pelvic pain, anxiety etc. occurring during pregnancy is very common. Among the most widely used CAM methods are herbal medicine, acupuncture, acupressure, relaxation therapies, aromatherapy, moxibustion, massage, reflexology and homeopathy. ${ }^{17-22}$ Although data in the literature on the rates of using CAM in reducing constipation during pregnancy is very limited, the rates of CAM use in pregnancy-related problems are reported to be quite common in developed countries such as America (69\%), the United Kingdom (57\%) and Germany $(51 \%) .{ }^{23-25}$ Performing research to reveal the efficacy and safety of CAM methods in reducing the symptoms of pregnancy-related constipation is a realistic and urgent need.

Many women experience constipation during their pregnancy. Nowadays, interest in nonpharmacological methods has increased, rather than pharmacological methods, in reducing this constipation that develops due to pregnancy. Especially, it is very important for midwives in every period of women's life to know what CAM methods are. That's why in this systematic review, it was aimed to focus on articles analyzing the effectiveness of CAM methods used to reduce symptoms pregnancyrelated constipation.

\section{MATERIALS AND METHODS Design}

This study is a quantitative systematic review in which the PRISMA guidelines were used for the analysis of the studies. ${ }^{25}$ These guidelines ensure a clear and transparent review of the articles included in the study in terms of their integrity. This study focused on articles analyzing the effectiveness of CAM methods used to reduce symptoms pregnancyrelated constipation.

After the duplicate articles were removed, the study was carried out through a three-stage inclusion process:

1. Screening relevant articles according to their titles and abstracts,

2. Selection of articles based on the reading of the entire text,

3. Analysis of the texts

These 3 stages were analysis by at least two of the three referees independently of each other, one of whom not included in the study (AŞK, SD, NÇD)

\section{Search methods}

The study was carried out between January 2010 and March 2020 by retrospectively screening the publications that analyzed the effectiveness of CAM methods used to reduce pregnancy-related constipation. For this purpose, the databases were screened over the internet access networks of Kocaeli University and Kurklareli University using the following keywords: constipation [ MeSH Terms and free text terms] and (pregnancy [MeSH Terms and free text terms] or pregnant woman [MeSH Terms and free text terms] and ("Acupuncture" or "Acupressure" or "Massage" or "Herbal medicine" or "Aromatherapy" or "Music therapy" or "Homeopathy" or "Hypnosis" or "Meditation" or "Reflexology" or "Moxibustion" or "Ayurvedic Medicine" or "Ayurveda" or "Traditional Iranian Medicine") . 


\begin{tabular}{c|c|c}
$\begin{array}{c}\text { Volume: } 2 \text { Issue: } 2 \\
\text { Year: } 2021\end{array}$ & $\begin{array}{c}\text { Publisher } \\
\text { DOI: } 10.53811 / \text { ijtcmr.932397 }\end{array}$ & $\begin{array}{c}\text { International Journal of Traditional and Complementary } \\
\text { Medicine Research }\end{array}$ \\
Duzce University
\end{tabular}

\section{Search outcomes}

Original studies which met the following inclusion criteria were included in the study:

1- Randomized design, quasi-randomized trial, noncontrolled and non-randomized prospective studies

\section{2- Published in English or Turkish}

3- Published between January 2010 and March 2020 4-Interventions pregnancy-related constipation associated with one of the aforementioned CAM methods

5- Outcome measure which was focused on changes in constipation with one of the aforementioned CAM methods

\section{Quality appraisal}

The quality appraisal of the studies was performed in accordance with the Cochrane Handbook for Systematic Reviews of Interventions (Higgins and Green, version 5.1.0, updated in March 2011). ${ }^{27}$. Therefore, after the selection of each study, the quality of the studies was rated using different methods to evaluate different study designs.

Assessment of the risk of bias is part of conducting and reporting of any systematic review. In this context, the JADAD checklist was used to assess the risk of bias and the quality of randomized controlled trials in each study. ${ }^{28}$ This scale consists of 3 items: describing randomization, blinding and accountability (dropouts and withdrawals).

Scoring: If randomization was mentioned in the study, it was given 1 point and if the study was consistent with the randomization method, it was given 1 point. However, if the study was not consistent with the randomization method, 1 point was subtracted.

Blinding: One point was given if blinding was mentioned. Another 1 point was given if it was consistent with the blinding method. If not, 1 point was subtracted.

Finally, we assigned 1 point if the accountability was known; if there were no data, the reason should have been stated. In the Jadad rating, scoring ranges between 0 and 5 points. If the Jadad score was $\geq 3$ points, the study was considered a high-quality study, and if it was $\leq 2$ points, the study was considered a low-quality study. ${ }^{28-31}$

Similarly, the CONSORT checklist was used to assess the quality of study report. This quality assessment includes the following: identification of the structured abstract and title to find out whether the study was a randomized study, the rational and scientific background and description of the goals or hypothesis, the definition of research design and important changes, the criteria for the compliance with participants and the study environment, interventions including replication details for each group, results and changes in the results, sample size and interim analysis and stop guides, explanation of randomization, blindness and similarity of interventions, statistical methods and additional analyses, participant flow, losses and exclusions, recruitment and reasons for stopped trial, basic data, numbers analyzed, results, estimation and binary outcomes, subsidiary analysis, losses, limitations, generalization and interpretation. Studies that did not meet at least $70 \%$ of the items included in the CONSORT checklist were considered to contain significant methodological flaws.

In this systematic review, the quality of quasirandomized trial was assessed using the JBI Checklist. ${ }^{43}$ This measuring tool consists of 10 items. The JBI checklist is used to assess whether the following criteria are met in studies: cause and effect relationship, presence of a control group, whether the treatment and control groups undergo the same application, the number of variables examined before and after the intervention, exact definition of the follow-up process, whether the variables in the two groups are evaluated with the same measurement method, same measurement methods for the variables in the two groups, whether the appropriate statistical tests are used and whether the overall assessment is made. Whether the criteria are met or not is determined with the following options: "Yes", "no", "unclear" and "not applicable".

In addition, because there is no quality assessment scale to rate non-randomized, non-controlled and prospective observational studies, a scale was developed to assess the quality of the studies based on the criteria list proposed by the Observational OpenLabel Studies scale. The scale consists of 12 items. Whether the criteria were met or not was assessed with the "yes", "no" or "unclear" options. If a study met 9 or more of the 12 criteria, the study was considered to have a low risk of bias (RoB) and to be a high-quality study. If 6 to 8 of the 12 criteria were met, the study was considered to have a moderate RoB and to be a medium quality study. If only 5 or fewer of the criteria were met, the study was considered to have a high RoB and to be a low quality study.

\section{Data extraction}

The document included the following data: type of the CAM, name of the study, authors / publication year of the study, country where the study was conducted, type of study, place of study, inclusion criteria for the study and participants' age and gestational age, 
sample size, data collection tools, details of the intervention, and results.

\section{RESULTS}

\section{Study selection}

For the review, 14536 studies were selected. Of hem, 706 were excluded because they were not in English or Turkish, or they were duplicates. As a result, 706 studies were screened based on their titles and abstracts. Seventy-three studies were analyzed in detail to assess whether they were suitable by two of the authors. They determined whether the title and abstract met the inclusion criteria.

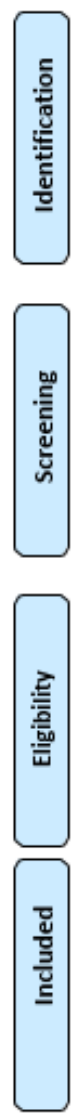

\section{Study characteristics}

We reached the final stage on these 3 studies conducted between January 2010 and March 2020 to investigate the effects of CAM methods on women suffering from constipation during pregnancy. These studies were a randomized controlled trial (RTC), a quasi-experimental studies and non-randomized, non-controlled and prospective observational study conducted on herbal medicine $(\mathrm{n}=2)$ and reflexology $(n=1)$. The number of the participants in the samples of the studies varied between 20 and 74 . The ages of the pregnant women participating in them ranged between 16 and 45 .
In order to find a larger number of original articles, of the studies in the reference lists of these studies, those found in the electronical environment were screened, but no studies were found to meet the inclusion criteria. In case of disagreement between the authors, the referees reached a decision after discussing the matter. In case they did not reach a decision, the opinion of the third referee who was not involved in the study was asked.

Finally, 3 studies were included in the study. The process was illustrated in a flow diagram in Figure 1. Detailed information of these 3 studies was summarized in Table 1.

Figure 1. Study selection process.

Additional records identified through other sources

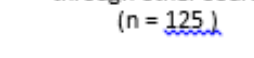

Studies included in

qualitative synthesis $(n=3)$ 
Volume: 2 Issue: 2

Year: 2021

DOI: $10.53811 /$ ijtcmr.932397

International Journal of Traditional and Complementary

Medicine Research
Publisher

Duzce University

Table 1. Complementary and alternative therapies for pregnant women suffer from constipation: a systematic review.

\begin{tabular}{|c|c|c|c|c|c|c|c|c|c|c|c|c|c|}
\hline Type of CAM & $\begin{array}{l}\text { Title of } \\
\text { manuscript }\end{array}$ & $\begin{array}{l}\text { First } \\
\text { Author } \\
\text { Year }\end{array}$ & Country & $\begin{array}{l}\text { Type of } \\
\text { study }\end{array}$ & Place & $\begin{array}{l}\text { Gestational } \\
\text { weeks/ } \\
\text { İncluded } \\
\text { criterias }\end{array}$ & Age & $\begin{array}{l}\text { Sample } \\
\text { size }\end{array}$ & $\begin{array}{l}\text { Tools of } \\
\text { data }\end{array}$ & $\begin{array}{l}\text { Treatment } \\
\text { arm }\end{array}$ & $\begin{array}{l}\text { Control } \\
\text { arm }\end{array}$ & Primary outcome & Quality \\
\hline $\begin{array}{l}\text { Herbal } \\
\text { Medicine } \\
\text { (Daikenchuto) }\end{array}$ & $\begin{array}{l}\text { Efficacy and } \\
\text { safety of } \\
\text { daikenchuto (TJ- } \\
100 \text { ) in pregnant } \\
\text { women with } \\
\text { constipation }\end{array}$ & $\begin{array}{l}\text { Touda et } \\
\text { al., 2016 } \\
\text { [31] }\end{array}$ & Japon. & $\begin{array}{l}\text { Prospective } \\
\text { Observational } \\
\text { Open-label } \\
\text { trial (A } \\
\text { prospective } \\
\text { interventional } \\
\text { one-arm } \\
\text { study) }\end{array}$ & Hospital & $\begin{array}{l}\text {-14-28 w } \\
\text { - Suffering with } \\
\text { constipation } \\
\text { during } \\
\text { pregnancy } \\
\text { period. }\end{array}$ & -Unclear & 20 & $\begin{array}{l}\text { Constipation } \\
\text { assessment } \\
\text { scale (CAS) }\end{array}$ & $\begin{array}{l}\text { The patients } \\
\text { received } 7.5 \mathrm{~g} / \mathrm{day} \\
\text { of daikenchuto for } \\
28 \text { days from the } \\
\text { day of } \\
\text { registration. }\end{array}$ & No & $\begin{array}{l}\text { Daikenchuto is } \\
\text { reliable and } \\
\text { effective in the } \\
\text { treatment of } \\
\text { pregnancy-related } \\
\text { constipation }\end{array}$ & $\begin{array}{l}\text { Observational } \\
\text { Open-Label } \\
\text { Studies scale: } \\
11 / 12 \text { yes } \\
1 / 12 \text { no }\end{array}$ \\
\hline $\begin{array}{l}\text { Herbal } \\
\text { Medicine } \\
\text { (Glucomana) }\end{array}$ & $\begin{array}{l}\text { The effect of } \\
\text { glucomannan on } \\
\text { pregnancy } \\
\text { constipation }\end{array}$ & $\begin{array}{l}\text { Janani and } \\
\text { Changaee, } \\
2018 \text { [32] }\end{array}$ & Iran & $\begin{array}{l}\text { Non } \\
\text { randomized } \\
\text { control study }\end{array}$ & Hospital & $\begin{array}{l}\text { - Unclear } \\
\text { gestational } \\
\text { weeks } \\
\text { - Suffering with } \\
\text { constipation } \\
\text { during } \\
\text { pregnancy } \\
\text { period. }\end{array}$ & -Unclear & 64 & $\begin{array}{l}\text { Questionnaire } \\
\text { (demographi, } \\
\text { reproductive } \\
\text { characteristic, } \\
\text { information } \\
\text { about } \\
\text { constipation). }\end{array}$ & $\begin{array}{l}-4 \mathrm{~g} \text { of powdered } \\
\text { glucomannan in } \\
\text { two divided doses } \\
\text { of moming and } \\
\text { night with a glass } \\
\text { of water. }\end{array}$ & $\begin{array}{l}- \text { The } \\
\text { magnesium } \\
\text { hydroxide was } \\
\text { been asked to } \\
\text { take a } \\
\text { tablespoon of } \\
\text { the drug each } \\
\text { night. }\end{array}$ & $\begin{array}{l}\text { The use of } \\
\text { glucomannan in } \\
\text { the treatment of } \\
\text { pregnancy-related } \\
\text { constipation is } \\
\text { very effective and } \\
\text { it does not lead to } \\
\text { serious } \\
\text { complications }\end{array}$ & $\begin{array}{l}\text { JBI: } \\
5 / 9 \text { yes } \\
1 / 9 \text { no } \\
3 / 9 \text { unclear }\end{array}$ \\
\hline $\begin{array}{l}\text { Foot } \\
\text { Reflexology }\end{array}$ & $\begin{array}{l}\text { The effect of } \\
\text { short-term foot } \\
\text { reflexology in } \\
\text { improving } \\
\text { constipation } \\
\text { symptoms during } \\
\text { pregnancy: A two- } \\
\text { armed, } \\
\text { randomized } \\
\text { controlled trial }\end{array}$ & $\begin{array}{l}\text { Sehbatti et } \\
\text { al.,2020 } \\
{[33]}\end{array}$ & Iran & $\begin{array}{l}\text { Randomized } \\
\text { blinded } \\
\text { control trial } \\
\text { study }\end{array}$ & $\begin{array}{l}\text { Health } \\
\text { care } \\
\text { centers }\end{array}$ & $\begin{array}{l}-23-28 \mathrm{w} \\
\text {-Having a score } \\
\text { of } 9 \text { to } 16 \text { based } \\
\text { on a CAS }\end{array}$ & $\begin{array}{l}16-45 \\
\text { years of } \\
\text { age }\end{array}$ & 74 & $\begin{array}{l}\text {-Constipation } \\
\text { Assessment } \\
\text { Scale (CAS). } \\
\text { - State-Trait } \\
\text { Anxiety } \\
\text { Inventory } \\
\text { (STAI) }\end{array}$ & $\begin{array}{l}\text {-Foot reflexology } \\
\text { was performed for } \\
\text { a short period of } \\
\text { time for } 6 \text { weeks } \\
\text { for } 12 \text { minutes. }\end{array}$ & -Standard care & $\begin{array}{l}\text { Short-term foot } \\
\text { reflexology } \\
\text { reduces the } \\
\text { symptoms of } \\
\text { constipation and } \\
\text { anxiety during } \\
\text { pregnancy }\end{array}$ & $\begin{array}{l}\text { JADAD: } \\
4 / 5\end{array}$ \\
\hline
\end{tabular}




\section{Interventions characteristics}

Of the CAM methods, herbal medicine was used in two of the 3 studies included in the study, and reflexology was used in the third one.

\section{Herbal medicine Intervention}

Two of the 3 studies included in our review were on herbal medicine interventions. One of them was a Prospective Observational Open-label trial (A prospective interventional one-arm study) conducted by Tsuda et al. (2016), in which Daikenchuto (TJ100), a traditional Japanese herbal medicine, was used. $^{32}$ The sample of this study performed in Japan comprised 20 pregnant women whose gestational age ranged between 14 and 28 weeks. The "Constipation assessment scale" (CAS) was used to assess constipation in the participating women. Daikenchuto (7.5 g / day) was administered to the participating pregnant women for 28 days. At the end of the study, Daikenchuto was determined to be effective and reliable in reducing the symptoms of constipation during pregnancy. The study was rated using the Observational Open-Label Studies scale and was given 11 points out of 12 .

The other 2 studies in which herbal medicine interventions were used was a non-randomized control study conducted by Janani and Changaee $(2018) .^{33}$ They administered a plant called Glucomannan used in various diseases to the patients. In this study conducted with 64 pregnant women in Iran, the questionnaire (demographic and reproductive characteristics of the participants, information about constipation) created by the researchers was used to assess constipation in pregnant women. In the study, the participants in the experimental group drank a glass of water including glucomannan. The total dose (4 g / day) of glucomannan was divided into two and administered twice a day in the morning and in the evening for one month days. The participants in the control group were given 1 tablespoon of magnesium hydroxide every night for one month. At the end of the study, it was stated that glucomannan was quite effective in the treatment of pregnancy-related constipation with no serious complications. The study was rated using the JBI checklist and was given 5 points out of 9 .

\section{Reflexology intervention}

The third of the 3 studies reviewed was a study of foot reflexology. The study conducted by Sehhatti et al. (2020) is a randomized blinded control trial study. ${ }^{34}$ The study sample comprised 74 Iranian pregnant women aged between 16 and 45 year. Their gestational age ranged between 23 and 28 weeks. In the study, the Constipation Assessment Scale (CAS) and State-Trait Anxiety Inventory (STAI) were used to assess constipation and other symptoms suffered by the participants. Those with a CAS score of 9-16 were especially included in the study. The participants in the experimental group underwent a 12-minute foot reflexology session per week for 6 weeks. The participants in the control group were given standard care. At the end of the study, foot reflexology was determined to decrease pregnancyrelated constipation and anxiety. The study was rated using the JADAD checklist and was given 4 points out of 5 .

\section{DISCUSSION}

This systematic review was conducted to determine the effects of CAM methods such as herbal medicine and reflexology on reducing constipation during pregnancy. Our review included 3 studies conducted in 2 countries between January 2010 and March 2020 with 158 pregnant women suffering from constipation. Of the 3 studies, 1 was about the use of foot reflexology and 2 were about the use of herbal medicines.

In one of the 2 studies about the use of herbal medicines, Daikenchuto (TJ-100), a traditional Japanese herbal medicine, was administered. This herbal extract consists of four active ingredients, including processed ginger, ginseng, Japanese zanthoxylum bark and koi (maltose powder). In the literature, Daikenchuto plant is known to affect gastrointestinal motility and microcirculation and to have anti-inflammatory effect. ${ }^{35,36}$ In a prospective randomized controlled study conducted with 39 patients with esophageal cancer in Japan, treatment with Daikenchuto was found to improve gastrointestinal motility after esophageal cancer resection. ${ }^{36}$ According to Hosaka et al.' metaanalysis (2019), daikenchuto, administered to patients with gastrointestinal system cancer in the postoperative period, was determined to improve intestinal dysfunction. ${ }^{37}$ In a study conducted with 22 patients with chronic constipation, daikenchuto reduced constipation-related bloating and abdominal pain. ${ }^{38}$ The results of another study conducted with 34 patients with stroke suffering from constipation problems revealed that daikenchuto could treat functional constipation, improved clinical constipation scores and decreased the intestinal gas volume. ${ }^{39}$

While there are no domestic (Turkish) studies on the use of CAM methods to reduce the symptoms of pregnancy-related constipation, there are many studies conducted abroad, but these studies included small sample sizes. In order for the applications to 


\section{Volume: 2 Issue: 2 \\ Year: 2021 \\ DOI: $10.53811 /$ ijtcmr.932397

have evidence-based value, randomized controlled experimental studies to be conducted in the future should have larger samples.

Glucomannan is one of the medicinal herbs widely used in the treatment of various diseases. This plant prevents stool from hardening, prevents the retention of feces in the rectum, and thus increases bowel movements. ${ }^{33,40}$ In the literature, although there are several studies indicating the effect of glucomannan on the symptoms of constipation especially in children, ${ }^{41,42,44}$ there is only one study investigating its effect on pregnant women. ${ }^{33}$ In Staiano et al.'s randomized controlled study conducted with 20 pediatric patients with a brain injury (2004), glucomannan increased the frequency of defecation (stool frequency), but had no effect on the colon motility. ${ }^{42}$ In their experimental study conducted with 31 children suffering from chronic constipation (2004), Loening-Baucke et al. found that glucomannan was effective in the treatment of constipation. ${ }^{41}$ In their systematic review including 8 studies conducted with children (2017), Han et al. reported that glucomannan moderately increased the frequency of defecation in children with constipation, but did not decrease stool consistency or did not lead to a general improvement in the treatment success. ${ }^{44}$ Although the results of these studies indicate that glucomannan had positive effects, side effects of glucomannan remain unknown due to the small sizes of the samples. Therefore, given the small sample size and the risk status of the side effects, the results of these studies should be interpreted more carefully.

The third study included in our review was a study of foot reflexology. Reflexology is a massage technique applied to the hands, soles of the feet and ears under certain rules. ${ }^{45}$ Reflexology is a non-invasive and safe intervention method. The review of the literature demonstrated that reflexology reduced pain, anxiety, depression, fatigue, symptoms related to gastrointestinal tract and constipation, and improved immune functions, and quality of sleep and life. ${ }^{46,47}$ In Sajadi et al.'s randomized controlled study conducted with 63 patients with multiple sclerosis (MS) who underwent foot reflexology (2020), this method was found to reduce the symptoms of constipation. ${ }^{47}$ Similarly, in another study performed with 40 children with cerebral palsy suffering from constipation, foot reflexology helped relieve constipation. ${ }^{45}$ In their study (2017), Canbulat and Demirgoz reported that foot reflexology did not make a statistically significant difference in stool consistency and the number of defecation in 37 children with functional constipation. ${ }^{46}$ The number of studies investigating the effect of foot reflexology on constipation is rather limited, and what is more, these studies included small sample sizes. In addition, in the literature, there is no systematic review or meta-analysis investigating the effect of foot reflexology on constipation

\section{Limitations}

The main problem encountered during our review was that the studies were very few. There was no study conducted on each CAM therapy. The studies available differed from each other in terms of the method investigated and sample sizes. In addition, due to language limitation, not all studies were reached. Therefore, the review was completed with 3 clinical studies.

\section{Strengths}

This study evaluating CAM methods for reducing the symptoms of pregnancy-related constipation is the first high-degree systematic review in terms of the period in which the articles were published, the number of studies examined and the number of databases. The most noteworthy strength of the study was that it revealed that the number of studies on the effects of CAM on the reduction of the symptoms of pregnancy-related constipation was very few, and that in the future, on this issue, more studies with larger samples should be conducted.

\section{CONCLUSION}

Diagnosis and treatment in CAM is often complicated. Although the duration of interventions for each CAM method was determined in some studies, this cannot be generalized to all CAM treatments. Today, in the medical literature, more studies should be carried out to provide evidence of molecular biology for the use of CAM methods in individual diagnosis and intervention within the framework of the concept of "Individualized Medicine". ${ }^{7}$ CAM methods used in reducing the symptoms of pregnancy-related constipation differ from one study to another, in terms of the type of the study, and the application method, measurement tools and assessment methods used in the study. This systematic review of 3 studies ( 2 on the use of herbal medicine and 1 on the use of foot reflexology) demonstrated that the methods used in these 3 studies were effective in reducing the symptoms of pregnancy-related constipation. In order to provide valid evidence on the long-term safety of CAM applications, a large number of well-designed randomized controlled trials with larger samples should be performed in the future. 
Volume: 2 Issue: 2

Year: 2021

DOI: $10.53811 /$ ijtcmr.932397
International Journal of Traditional and Complementary

Medicine Research
Publisher

Duzce University

\section{REFERENCES}

1. Trottier M, Erebara A, Bozzo P. Treating constipation during pregnancy. Canadian Family Physician. 2012; 58(8): 836838 .

2. Shin GH, Toto EL, Schey R. Pregnancy and postpartum bowel changes: constipation and fecal incontinence. The American Journal of Gastroenterology. 2015; 110(4): 521.

3. Rungsiprakarn P, Laopaiboon M, Sangkomkamhang US, Lumbiganon P, Pratt JJ. Interventions for treating constipation in pregnancy. Cochrane Database of Systematic Reviews. 2015; (9).

4. Kaya R, The state of the prevalence of constipation in pregnancy and its relation department of midwifery, MA Thesis, Aydin, 2018.

5. Kılıçarslan S, Sociodemographic characteristics, health qualities and anxiety levels of third trimester pregnant women living in edirne, Trakya university faculty of medicine department of family medicine, MA Thesis, Edirne, 2008.

6. Cullen G, O'Donoghue D. Constipation and pregnancy. Best Practice \& Research Clinical Gastroenterology. 2007; 21(5): 807-818.

7. Paknejad MS, Motaharifard MS, Barimani S, Kabiri P, Karimi M. Traditional, complementary and alternative medicine in children constipation: A systematic review. Daru. 2019; 27(2): 811-826.

8. Wald A. Constipation, diarrhea, and symptomatic hemorrhoids during pregnancy. Gastroenterology Clinics of North America. 2003; 32(1): 309-22, vii.

9. Derbyshire E, Davies J, Costarelli V, Dettmar P. Diet, physical inactivity and the prevalence of constipation throughout and after pregnancy. Maternal \& Child Nutrition. 2006; 2(3): 127-34.

10. Shamim S, Begum A. Functional constipation in pregnancy; need to furnish some more emphasis. Annals of Abbasi Shaheed Hospital and Karachi Medical \& Dental College. 2019; 24(2): 96-102

11. Van Brummen HJ, Bruinse, HW, van de Pol G, Heintz APM, van Huub C. Defecatory symptoms during and after the first pregnancy: prevalences and associated factors. International Urogynecology Journal of Pelvic Floor Dysfunction. 2006; 17: 224-30.

12. Zhai J, Li Y, Lin J, Dong S, Si J, Zhang J. Chinese herbal medicine for postpartum constipation: a protocol of systematic review and meta-analysis. BMJ open. 2019; 9(1).

13. Body C, Christie JA. Gastrointestinal diseases in pregnancy: nausea, vomiting, hyperemesis gravidarum, gastroesophageal reflux disease, constipation, and diarrhea. Gastroenterology Clinics. 2016; 45(2): 267-283.

14. Briggs GG, Freeman RK, Yaffe SJ. Drugs in pregnancy and lactation. 9th ed. Philadelphia: Lippincott Williams \& Wilkins; 2011

15. Prather CM. Pregnancy-related constipation. Current Gastroenterology Reports. 2004; 6(5): $402-4$.

16. National Centre for Complementary and Integrative Health Medicine (NCCIH), 2017. Retrieved from(nccih.nih.gov) Feb 2017

17. Alimoradi Z, Kazemi, F, Valiani M, Gorji M. Comparing the effect of auricular acupressure and body acupressure on pain and duration of the first stage of labor: study protocol for a randomized controlled trial. Trials. 2019; 20(1): 1-8.

18. Hall H, Griffiths M, McKenna L. The use of complementary and alternative medicine by pregnant women: a literature review. Midwifery. 2011; 27: 817-824.

19. Miyoung C, Euysoon CA. Comparison between effects of aroma massage and meridian massage on constipation and stress in women college students. Journal of Korean Academy of Nursing. 2011; 41(1).

20. Ozgoli G, Naz MSG. Effects of complementary medicine on nausea and vomiting in pregnancy: A systematic review. International Journal of Preventive Medicine. 2019;9.

21. Yao X, Li C, Ge X, Wei J, Luo J, Tian F. Effect of acupuncture on pregnancy related low back pain and pelvic pain: a systematic review and meta-analysis. International Journal of Clinical Experimental Medicine. 2017; 10(4): 5903-5912.

22. Zhou J, Liu Y, Zhou K, Liu B, Su T, Wang W, Liu Z. Electroacupuncture for women with chronic severe functional constipation: subgroup analysis of a randomized controlled. Trial BioMed Research international. 2019.

23. Hall HR, Jolly K. Women's use of Complementary and Alternative Medicines during pregnancy: a cross-sectional study. Midwifery. 2013; 30: 499-505.

24. Kalder M, Knoblauch K, Hrgovic I, Munstedt K. Use of complementary and alternative medicine during pregnancy and delivery. Archives of Gynecology and Obstetrics. 2011; 283: 475-482.

25. Strouss L, Macklay A, Guillen U, Paul D, Locke R. Complementary and Alternative Medicine use in women during pregnancy: do their healthcare providers know?. BioMed Central Complementary and Alternative Medicine. 2014; 14: 85.

26. Moher D, Liberati A, Tetzlaff J, Altman DG. Preferred reporting items for systematic reviews and meta-analyses: The PRISMA statement. Annals of Internet Medicine. 2009; 151(4): 264-269.

27. Higgins JPT, Thomas J, Chandler J, Cumpston M, Li T, Page MJ, Welch VA (editors). Cochrane handbook for systematic reviews of interventions version 6.0 (updated July 2019). Cochrane, [Accessed
[A

2019-03-06] www.training.cochrane.org/handbook.

28. Jadad AR, Moore RA, Carroll D, Jenkinson C, Reynolds DJM, Gavaghan DJet al Assessing the quality of reports of randomized clinical trials: is blinding necessary? Controlled Clinical Trials. 1996; 17(1): 1-12.

29. Espí-López GV, Arnal-Gómez, A, Balasch-Bernat M, Inglés M. Effectiveness of manual therapy combined with 
Volume: 2 Issue: 2

Year: 2021

DOI: $10.53811 /$ ijtcmr.932397
International Journal of Traditional and Complementary

Medicine Research
Publisher

Duzce University

physical therapy in treatment of patellofemoral pain syndrome: systematic review. Journal Chiropractic Medicine. 2017; 16(2): 139-146.

30. Seminario-Amez M, López-López J, Estrugo-Devesa A, Ayuso-Montero R, Jané Salas E. Probiotics and oral health: A systematic review. Medicina Oral Patologia Oral Cirugia Bucal. 2017; 22(3): e282-e288.

31. Zhang H, Lan X, Penig B, Li B. Is total laparoscopic pancreaticoduodenectomy superior to open procedure? A metaanalysis. World Journal of Gastroenterolgy. 2019; 25(37): 5711-5731.

32. Tsuda H, Kotani T, Sumigama S, Mano Y, Hayakawa H, Kikkawa F. Efficacy and safety of daikenchuto (TJ-100) in pregnant women with constipation. Taiwan Journal of Obstetric \& Gynecology. 2016; 55(1): 26-9.

33. Janani F, Changaee F. The effect of glucomannan on pregnancy constipation. Journal Family Medicine Primarily Care. 2018; 7: 903-6.

34. Sehhatti F, Hughes C, Mirghafourvand M, Azan ZA. The Effect of short - term foot reflexology in improving constipation symptoms during pregnancy: a two-armed, randomized controlled trial. International Journal of Women's Health and Reproduction Sciences. 2020; 8(1): [4726]

35. Hoshino N, Kawada K, Hida K. Effect of Daikenchuto (TJ-100) on gastrointestinal symptoms following laparoscopic colectomy in patients with colon cancer: study protocol for a randomized controlled trial. Trials. 2017; $18: 553$.

36. Nishino T, Yoshida T, Goto M. The effects of the herbal medicine Daikenchuto (TJ-100) after esophageal cancer resection, open-label, randomized controlled trial. Esophagus. 2018; 15: 75-82.

37. Hosaka M, Arai I, Ishiura Y, Seki T, Naito Y, Mottoo Y. et al., Efficacy of daikenchuto, a traditional Japanese Kampo medicine, for postoperative intestinal dysfunction in patients with gastrointestinal cancers: meta-analysis. International Journal of Clinical Oncology. 2019; 24: 1385-1396

38. Horiuchi A, Nakayama Y, Tanaka N. Effect of traditional japanese medicine daikenchuto (tj-100) in patients with chronic constipation. Gastroenterology Research. 2010; 3(4): 151-155.

39. Numata T, Takayama S, Tobita M. Traditional japanese medicine daikenchuto improves functional constipation in poststroke patients. Evidence-Based Complementary and Alternative Medicine. 2014; 8.

40. González Canga A, Fernández Martínez N, Sahagún AM, García Vieitez JJ, Díez Liébana MJ, Calle Pardo AP. et al. Glucomannan: properties and therapeutic applications. Nutricion Hospitalaria. 2004; 19: 45-50.

41. Loening-Baucke V, Miele E, Staiano A. Fiber (Glucomannan) is beneficial in the treatment of childhood constipation. Pediatrics. 2004; 113 (3): e259-e264.

42. Staiano, A, Simeone D, Del Giudice E et al. Effect of the dietary fiber glucomannan on chronic constipation in neurologically impaired children. The Journal of Pediatrics. 2000; 136(1): 41-45.

43. JBI critical appraisal checklist for quasi-experimental studies. 2019, https:// wiki.joannabriggs.org/pages/viewpage.action?pageId=9273720.

44. Han Y, Zhang L, Liu XQ, Zhao ZJ, Lv LX. Effect of glucomannan on functional constipation in children: a systematic review and meta-analysis of randomized controlled trials. Asia Pacific Journal of Clinical Nutrition. 2017; 26(3): 471477

45. Elbasan B, Bezgin S. The effects of reflexology on constipation and motor functions in children with cerebral palsy. Pediatrics \& Neonatology. 2018; 59(1): 42-47.

46. Canbulat Sahiner N, Demirgoz Bal M. A Randomized controlled trial examining the effects of reflexology on children with functional constipation. Gastroenterology Nursing. 2017; 40(5): 393-400.

47. Sajadi M, Davodabady F, Naseri-Salahshour V, Harorani, M, Ebrahimi-Monfared M The effect of foot reflexology on constipation and quality of life in patients with multiple sclerosis. A randomized controlled trial. Complementary Therapies Medicine. 2020; 48: 102270. 